\title{
Pathways for Low-Carbon Transition of the Steel Industry-A Swedish Case Study
}

\author{
Alla Toktarova ${ }^{1, *}$, Ida Karlsson ${ }^{1} \mathbb{D}$, Johan Rootzén ${ }^{2} \mathbb{D}$, Lisa Göransson ${ }^{1}$, \\ Mikael Odenberger ${ }^{1}$ and Filip Johnsson ${ }^{1}$ \\ 1 Department of Space, Earth and Environment, Chalmers University of Technology, \\ SE-412 96 Gothenburg, Sweden; ida.karlsson@chalmers.se (I.K.); lisa.goransson@chalmers.se (L.G.); \\ mikael.odenberger@chalmers.se (M.O.); filip.johnsson@chalmers.se (F.J.) \\ 2 Department of Economics, University of Gothenburg, SE-405 30 Gothenburg, Sweden; \\ johan.rootzen@economics.gu.se \\ * Correspondence: alla.toktarova@chalmers.se
}

Received: 30 June 2020; Accepted: 20 July 2020; Published: 27 July 2020

\begin{abstract}
The concept of techno-economic pathways is used to investigate the potential implementation of $\mathrm{CO}_{2}$ abatement measures over time towards zero-emission steelmaking in Sweden. The following mitigation measures are investigated and combined in three pathways: top gas recycling blast furnace (TGRBF); carbon capture and storage (CCS); substitution of pulverized coal injection (PCI) with biomass; hydrogen direct reduction of iron ore (H-DR); and electric arc furnace (EAF), where fossil fuels are replaced with biomass. The results show that CCS in combination with biomass substitution in the blast furnace and a replacement primary steel production plant with EAF with biomass (Pathway 1) yield $\mathrm{CO}_{2}$ emission reductions of $83 \%$ in 2045 compared to $\mathrm{CO}_{2}$ emissions with current steel process configurations. Electrification of the primary steel production in terms of H-DR/EAF process (Pathway 2), could result in almost fossil-free steel production, and Sweden could achieve a $10 \%$ reduction in total $\mathrm{CO}_{2}$ emissions. Finally, (Pathway 3 ) we show that increased production of hot briquetted iron pellets (HBI), could lead to decarbonization of the steel industry outside Sweden, assuming that the exported HBI will be converted via EAF and the receiving country has a decarbonized power sector.
\end{abstract}

Keywords: iron and steel industry; techno-economic pathways; decarbonization; $\mathrm{CO}_{2}$ emissions; carbon abatement measures

\section{Introduction}

In Sweden, the industrial sector is responsible for over a third of the total energy demand. In 2017, the iron and steel industry was the largest industrial consumer of fossil fuels (natural gas, oil, coal and coke) and the resulting $\mathrm{CO}_{2}$ emissions corresponded to $38 \%$ of the total industrial $\mathrm{CO}_{2}$ emissions in Sweden [1]. In line with the global effort of keeping the temperature increase to well below $2{ }^{\circ} \mathrm{C}$, Sweden introduced a nationwide climate policy framework which entered into force in 2018. Through this new framework, Sweden has formally committed to net zero greenhouse gas emissions by 2045 compared to the level in 1990, translating into at least $85 \%$ reduction in emissions with the remaining emission reduction to be taken by bio-carbon capture and storage (CCS), land-use change and measures in other countries. After 2045 Sweden is to achieve net negative emissions [2]. The Swedish steel-producing sector is facing the challenge of changing current energy carriers and implementing low carbon technologies to meet these targets.

To reach substantial cuts in emissions from the energy-intensive industries has proven to be challenging [3]. Bataille et al. [4] categorize the general decarbonization options for the energy-intensive 
industries by a decision-tree with three main branches, (i) dematerialization or recycle/reuse, (ii) substantial changes of existing processes, (iii) maintaining existing processes with CCS or using an alternative heat source. Johansson et al. [5] investigate measures for the Swedish steel industry that enable becoming climate neutral and conclude that in order to reach deep emissions cuts, efficient energy use must be combined with alternative technologies such as fuel replacement and CCS. Wang et al. [6] investigate the deployment of biomass in the Swedish integrated steel plants applying an energy and mass balance model. The findings by Wang et al. show that using biomass to replace coal in one single blast furnace (the blast furnace located in Luleå), would decrease the $\mathrm{CO}_{2}$ emissions of the entire Swedish steel industry by $17.3 \%$. Yet, this would require 6.19 TWh of biomass, which correspond to about $4 \%$ of current (2017) annual biomass harvests from the Swedish forest industry, while there are several sectors that will compete over the biomass resource. Furthermore, Mandova et al. [7] use a techno-economic model to estimate the carbon dioxide emissions mitigation potential of bio-CCS in primary steelmaking across the European Union (EU). They demonstrate that up to $20 \%$ of the EU $\mathrm{CO}_{2}$ emission reduction target can be met entirely by biomass deployment, and up to $50 \%$ by bio-CCS . Lechtenbohmer et al. [8] investigate electrification of the energy-intensive basic materials industry in the EU by means of an explorative method and conclude that electrification of the production of basic materials is technically feasible, yet, can have major implications on the interaction between the industries and the electric systems.

Fischedick et al. [9] have developed a techno-economic model to assess the potential of alternative processes for primary steel production, e.g., blast furnace with $\mathrm{CCS}$ (BF/CCS), hydrogen direct reduction, and direct electrolysis of iron ore. The study is made for Germany and the model is run for scenarios up to the year 2100. According to the study, the $80 \%$ emission reduction target defined by European Commission (EC) for the iron and steel industry can only be met with early implementation of alternative technologies such as hydrogen direct reduction and iron ore electrolysis, together with a strong climate policy and additional material efficiency measures.

The findings by Fischedick et al. [9] are confirmed by Arens et al. [10] who analyze four future pathways to a low-carbon steel production industry in Germany up to 2035 with emphasis put on estimating technical options, specific energy consumption and $\mathrm{CO}_{2}$ emissions in the German steel industry. Even though Arens et al. [10] have a different time perspective than Fischedick et al. [9] they conclude that, in order to reduce carbon dioxide emissions from steel production to near zero, alternative steelmaking processes (hydrogen direct reduction, steel electrolysis) need to be developed while $\mathrm{CO}_{2}$ reduction in short-term (heat recovery, scrap usage and the use of by-products to produce base chemicals) also need to be realized. Although the above works give important knowledge on the available options for abatement of carbon emissions from steel production, there is a lack of studies which shows how a transition from today's steel industry to a near zero-emitting steel industry could be allocated in time.

Therefore, using Sweden as an example, this study aims to further investigate the potential development of the iron and steel industry to become carbon neutral (by 2045, as it is the Swedish target year for carbon neutrality) with respect to the dynamics of the transition, i.e., which technology options to use and when it is reasonable to assume these can be implemented in the form of decarbonization pathways. We consider recent developments in the Swedish iron and steel industry as well as a general literature review on emission reductions options in the iron and steel industry. In addition, barriers and risks associated with developed pathways are put forward and discussed.

The outline of the paper is as follows: Section 2 gives an overview of the Swedish steel industry. Section 3 presents the method and assumptions. Section 4 presents the results. The paper ends with discussion and conclusions in Sections 5 and 6.

\section{2. $\mathrm{CO}_{2}$ Abatement in the Steel Industry}

Sweden is one of the EU's leading producers of ores and metals; ore extraction is about 48 Mton annually of which $83 \%$ is refined into iron ore pellets. Furthermore, $77 \%$ of the iron ore extractions 
are exported, which correspond to about 17 Mton [11]. In Sweden, two different steel production technologies are currently applied: the ore-based steelmaking process using blast furnaces/basic oxygen furnaces $(\mathrm{BF} / \mathrm{BOF})$, and the scrap-based steel production applying electric arc furnaces (EAF) [12]. These processes have a different structure of the main inputs and energy intensity. The average annual production of crude steel in 2017 was around 4.9 Mt. Two-thirds of the steel production stems from the $\mathrm{BF} / \mathrm{BOF}$ technology, which currently takes place in two locations (Luleå and Oxelösund) by one single company (SSAB, Stockholm, Sweden). SSAB is accountable for more than $90 \%$ of the $\mathrm{CO}_{2}$ emissions from Swedish steel production, and about $80 \%$ of these emissions originate from iron ore reduction. Within the $\mathrm{BF} / \mathrm{BOF}$ process, iron ore is reduced to pig iron using reducing agents in a blast furnace. Furthermore, in a basic oxygen furnace (BOF) pig iron together with ferrous scrap is processed and transformed into crude steel. As a first step toward carbon-neutral steel production, SSAB has decided to replace the blast furnace in Oxelösund with an electric arc furnace by 2025 [13], when the current blast furnace is scheduled to be retired due to age. EAF requires ferrous scrap and electricity as major inputs. Oxygen and natural gas are used to generate complementary chemical heat for the melting. Based on the configuration of the EAF plant, the availability of scrap and the desired quality of the end product, this process may require some quantities of pig iron from the BF or, optionally, direct reduced iron (DRI). Secondary steelmaking with EAF results in producing lower steel quality compare to virgin steel since scrap steel retains contaminants, such as copper. Steel produced in an EAF tends to be of lower quality than virgin steel because it retains whatever contaminants that were present in the scrap steel, such as copper. Although the EAF is less energy- and $\mathrm{CO}_{2}$-intensive, high-quality virgin steel demand will remain.

The specific technological decarbonization options for the steel industry are found in Table 1, including information on $\mathrm{CO}_{2}$ intensity, costs and technology readiness level (TRL) [14].

Table 1. Specifications of current commercially available and new transformative low $\mathrm{CO}_{2}$ production processes for steel production in greenfield production facilities.

\begin{tabular}{|c|c|c|c|c|}
\hline Process & TRL Status & $\begin{array}{c}\mathrm{CO}_{2} \text { Emissions, } \\
\text { Tonne } \mathrm{CO}_{2} / \\
\text { Tonne Steel }\end{array}$ & $\begin{array}{c}\text { Capital } \\
\text { Expenses, } \\
\text { €/Tonne }\end{array}$ & References \\
\hline \multicolumn{5}{|l|}{ Primary steel production } \\
\hline $\begin{array}{l}\text { Blast furnace with basic oxygen } \\
\text { furnace }(\mathrm{BF} / \mathrm{BOF})\end{array}$ & Commercial (TRL 9) & $1.6-2.2$ & $386-442$ & {$[15,16]$} \\
\hline $\begin{array}{l}\text { Top gas recycling blast furnace } \\
\text { (TGRBF/BOF) }\end{array}$ & TRL 7 & $1.44-1.98$ & 632 & [17-19] \\
\hline $\mathrm{CO}_{2}$ capture technology ${ }^{1}$ & TRL 6-9 & $\begin{array}{c}\mathrm{CO}_{2} \text { capture } \\
\text { efficiency }(\%): 90\end{array}$ & $25-85$ & {$[17,20-23]$} \\
\hline Smelting reduction (SR/BOF) & Commercial (TRL 9) & $1.2-2.25$ & 393 & {$[15,21]$} \\
\hline $\begin{array}{l}\text { Direct reduction using electric } \\
\text { arc furnace (DR/EAF) }\end{array}$ & Commercial (TRL 9) & $0.63-1.15$ & 414 & {$[15,18,24]$} \\
\hline $\begin{array}{l}\text { Hydrogen direct reduction using } \\
\text { electric arc furnace (H-DR/EAF) }\end{array}$ & TRL 1-4 & 0.025 & $550-900$ & [25-27] \\
\hline Electrowinning (EW) & TRL 4-5 & $0.2-0.29$ & 639 & {$[9,25,28]$} \\
\hline \multicolumn{5}{|l|}{ Secondary steel production } \\
\hline Electric arc furnace (EAF) & Commercial (TRL 9) & 0.6 & 169-184 & {$[15,29,30]$} \\
\hline $\begin{array}{l}\text { Electric arc furnace/biomass } \\
\text { (EAF/biomass) }\end{array}$ & TRL 6-8 & 0.005 & $169-184$ & {$[26,31]$} \\
\hline
\end{tabular}

To assess the techno-economic potential of the $\mathrm{CO}_{2}$ emissions reduction in the steel industry the following $\mathrm{CO}_{2}$ emission reduction measures were selected and investigated: top gas recycling blast furnace (TGRBF); carbon capture and storage (CCS); substitution of pulverized coal injection (PCI) with biomass; steelmaking process with hydrogen direct reduction of iron ore (H-DR) and 
an electric arc furnace (EAF); and a secondary steel production route with EAF, where fossil fuels are replaced with biomass. Furthermore, the abatement measures are combined in three pathways to investigate the potential development implementation of these technologies over time towards zero-emission steelmaking.

The top gas recycling blast furnace concept relies on both removing the $\mathrm{CO}_{2}$ from the top gas and reinjection of the remaining gas to the blast furnace. This technology enables a decrease in carbon dioxide emissions from the blast furnace since the demand for coke reduces and an opportunity of $\mathrm{CO}_{2}$ storage. The TGRBF could be modified to an existing blast furnace [32].

As long as the blast furnace process uses coke and coal as fuels, $\mathrm{CO}_{2}$ emissions are unavoidable, but they could be reduced by means of biomass-derived fuels and reductants applications. The following potential biomass applications can be specified: replacement of fossil fuels in sintering or pelletizing; substitute for coke as a reducing agent and fuel in the blast furnace; substitute for pulverized coal injected (PCI) as a fuel in the blast furnace; substitute for coal-based char utilized for recarburizing the steel; and reduction of pre-reduced feeds [33]. The biomass substitution rate varies between applications. Since the replacement of PCI with biomass is the most feasible application [34], this option is investigated in the present study.

However, in order to achieve deep $\mathrm{CO}_{2}$ emission cuts down to zero or beyond zero, the steel industry must either capture the $\mathrm{CO}_{2}$ emissions or shift to another means of iron reduction (hydrogen direct reduction, steel electrolysis). The deployment of CCS in a steel plant is in this work considers the integration of post-combustion capture, which can reduce carbon dioxide emissions from existing plants without major modifications. According to Eurofer [15] a full-scale deployment of the TGR and CCS technologies is assumed possible after 2020. The potential for $\mathrm{CO}_{2}$ reduction is around 5-10\% from TGR alone, 50-60\% with TGR technology combined with carbon storage (TGRBF + CCS), and over $80 \%$ with TGR with biomass-based BF and carbon storage (TGRBF charcoal + CCS) $[35,36]$.

Currently, the main focus for $\mathrm{CO}_{2}$ mitigation of the steel industry in Sweden is to develop the hydrogen direct reduction of iron ore. In the present study, we assume hydrogen replaces coke as the main reductant in the reduction process and hydrogen is produced via electrolysis. Iron ore is converted into direct reduced iron (DRI) during the H-DR process and further compressed to hot briquetted iron (HBI), since HBI is less reactive than DRI and allows the problems associated with shipping and handling to be overcome. The principal market for HBI pellets is the electric arc furnace (EAF), but HBI also finds use as a feedstock in basic oxygen furnace (BOF). HBI pellets produced by the hydrogen direct reduction (H-DR) steelmaking process could decrease $\mathrm{CO}_{2}$ emissions from ironmaking by $90 \%$ compared with iron production in a blast furnace, and by $80 \%$ compared with a direct reduction of iron using natural gas, as a reducing agent. The hydrogen direct reduction steelmaking process is expected to be feasible from 2040 [37]. The alternative secondary steel-making process is based on the conventional EAF, however, the chemical energy and carbon required to complement the electrical energy is taken from biomass.

\section{Method}

\subsection{Techno-Economic Pathways Concept}

In this study, the concept of techno-economic pathways is used (Figure 1). The pathways are characterized as series of techno-economic investments connecting current steel industry configurations to a desirable low-carbon future [38]. The pathways reveal sectoral-level changes through technological characteristics. 


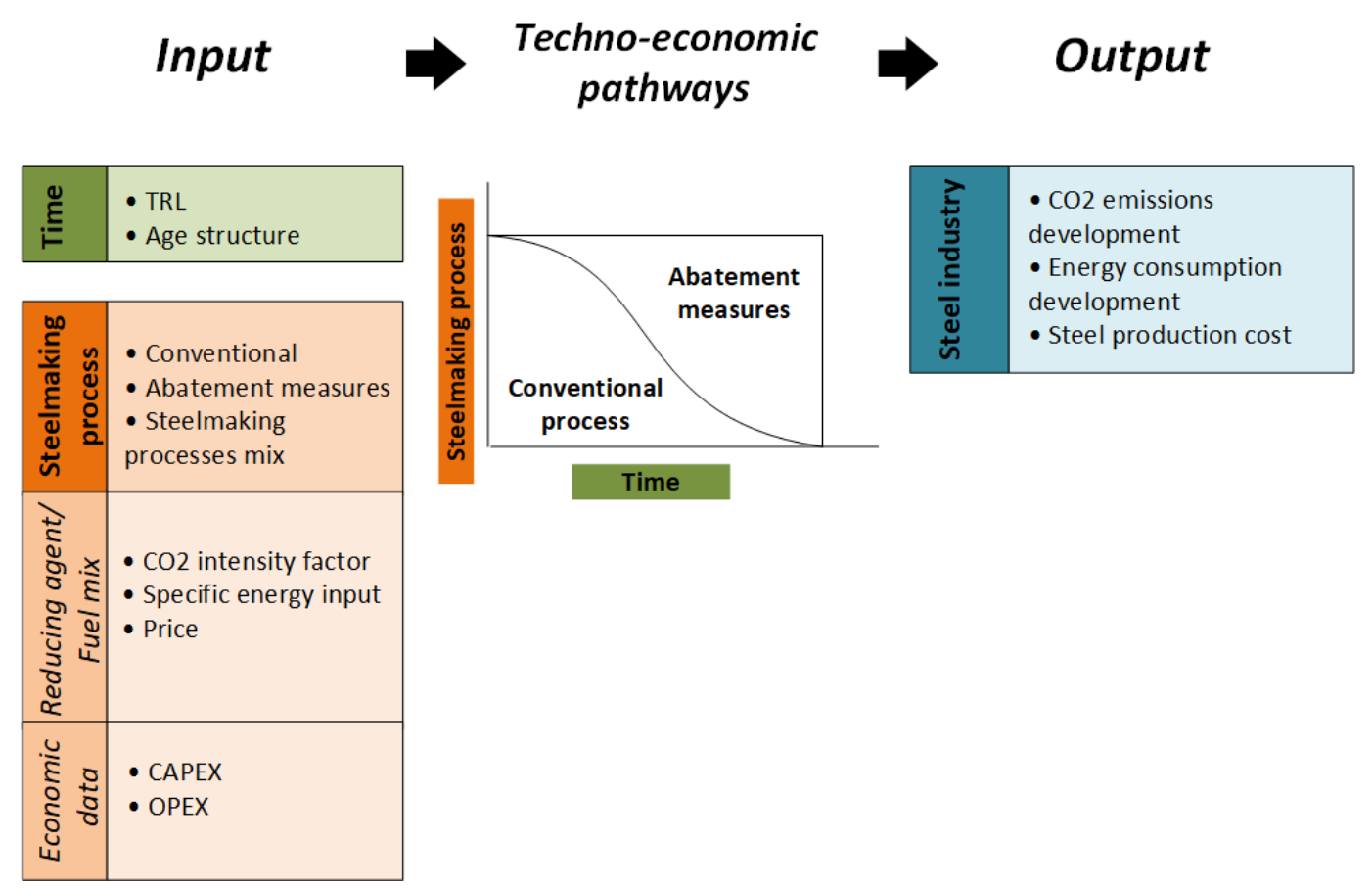

Figure 1. Schematic overview of the techno-economic pathways concept used in this work.

The pathway analysis follows the following steps:

- The assessment of $\mathrm{CO}_{2}$ abatement measures in the steel industry serves as inputs for the techno-economic pathways as it establishes an upper limit for the emission reduction potential.

- The selection and combination of the $\mathrm{CO}_{2}$ abatement measures are made in line with governmental climate goals and the visions of the steel companies, as well as a comprehensive literature review.

- The pace of retiring the conventional steelmaking technologies and replacing these with technologies which apply $\mathrm{CO}_{2}$ abatement measures is in accordance with the age structure of the existing capital stock and assumptions concerning the average technical lifetime of steelmaking technologies (capital stock turnover). The assumed average technical lifetime of steelmaking technologies is set to 50 years. A timeline of the development $\mathrm{CO}_{2}$ abatement measures throughout technology readiness levels phases, i.e., from concept design to technological maturation and deployment, has been generated based on [39] and industry reports prognosis.

- Based on the technology readiness level timeline, we estimate a timeline for investments in abatement measures to replace current processes, prompting a shift in innovative technology diffusion patterns. The technology readiness level is established by means of a literature review including industry and government agency reports (i.e., these are the ones listed in Table 1). The following outputs from the developed pathways are analysed: development of $\mathrm{CO}_{2}$ emissions and energy consumption over time and steel production cost.

Three mitigation pathways (Pathways 1-3) as defined in Table 2 are investigated for the Swedish steel industry applying a selected combination of the $\mathrm{CO}_{2}$ abatement measures listed in Table 1 . As a reference, we also compare these pathways to current steel process configuration, for which $65 \%$ of the steel production is based on the conventional primary steelmaking process using blast furnace and basic oxygen converter $(\mathrm{BF} / \mathrm{BOF})$ and $35 \%$ of the steel is produced in conventional electric arc furnaces (EAF). For Pathways 1 and 2 the total annual production of the Swedish steel industry is assumed to remain at 4.9 Mtonne (average steel production of Year 2017) between 2020 and 2045. For Pathway 3 , an ore based metallic production growth is assumed, i.e., hot briquetted iron pellets produced via H-DR process. The export of HBI pellets is arbitrarily assumed to reach $6 \mathrm{Mt}$ in 2045, which, since the iron content in HBI pellets is higher than in iron ore pellets, corresponds to approximately $50 \%$ of LKAB's 
iron ore pellets export in 2017. Table 2 shows the combination of $\mathrm{CO}_{2}$ abatement measures assumed for primary and secondary steelmaking and production rate level in the investigated pathways. The share of primary steelmaking is assumed to decrease compared to the current level for all pathways due to replacement of one of the blast furnaces by EAF in 2025 [13]. However, for Pathways 2 and 3, from 2040 the share between primary and secondary steelmaking is assumed to be on the current level [26]. The configurations do not include processes of steel casting, hot rolling, cold rolling and coating due to their relatively less energy consumption and carbon emissions.

Table 2. Overview of the process configurations as well as production rate assumption for pathways investigates.

\begin{tabular}{lccccc}
\hline Pathway & Primary Steelmaking & $\begin{array}{c}\text { Commercially } \\
\text { Available }\end{array}$ & $\begin{array}{c}\text { Secondary } \\
\text { Steelmaking }\end{array}$ & $\begin{array}{c}\text { Commercially } \\
\text { Available }\end{array}$ & $\begin{array}{c}\text { Production } \\
\text { Rate }\end{array}$ \\
\hline Pathway 1 & TGRBF/BOF + CCS + biomass & 2030 & EAF/biomass & 2025 & Constant \\
Pathway 2 & H-DR/EAF & 2040 & EAF/biomass & 2025 & Constant \\
Pathway 3 & H-DR/EAF & 2040 & EAF/biomass & 2025 & Increased \\
\hline
\end{tabular}

${ }^{1}$ Year when assumed commercially available.

\subsection{Data}

The assessment of the energy consumption and $\mathrm{CO}_{2}$ emissions is based on the specific energy consumption and carbon dioxide emission intensity per ton steel, as outlined for the investigated process configurations in Table A1 in Appendix A. Emissions arise from the combustion of biomass are discarded from the emission estimates (i.e., assuming that the biomass is sustainable from a carbon accounting point of view). The Swedish climate goal to get $100 \%$ of renewable electricity by 2040 [2] and the current (2017) $\mathrm{CO}_{2}$ emission grid factor is already low, equaling $0.069 \mathrm{kgCO}_{2} / \mathrm{kWh}^{2}$ [40]. The $\mathrm{CO}_{2}$ emission associated with electricity is assumed to fall linearly from $0.069 \mathrm{kgCO} / \mathrm{kWh}$ in the current year to zero by the year 2040. (see Appendix A, Table A2). An economic analysis based on steel production cost is conducted for technologies used in the investigated pathways. The total steel production cost is determined as the sum of capital and variable operating costs, where variable operating cost includes the cost of reducing agent, fuel and other costs associated with running the steel process (see Appendix A, Table A3).

\subsection{Modeling Pathways}

The annual energy consumption for steel production $\left(Q_{t, i}\right)$ in year $t$ for Pathway $i$ is calculated by applying the specific energy consumption of fuel and reducing agent combined with total annual crude steel production:

$$
Q_{t, i}=\sum_{j} \sum_{r} s_{r, j} x_{t, i, r} P, \quad t \in T, \quad i \in I
$$

where $s_{r, j}$ is specific energy consumption of fuel and reducing agent $j$ in the technology $r(\mathrm{kWh} / \mathrm{t})$. $P$ denotes total annual crude steel production (tonne) and $x_{t, i, r}$ represents the share of the production from the technology $r$ in year $t$ for pathway $i(\%)$.

For each pathway, the annual $\mathrm{CO}_{2}$ emissions from the steel production $E_{t, i}\left(\right.$ tonne $\left.\mathrm{CO}_{2}\right)$ in year $t$ are given by:

$$
E_{t, i}=\sum_{r} e_{r} x_{t, i, r} P, \quad t \in T, \quad i \in I
$$

where $P$ denotes total annual crude steel production (tonne), $e_{r}$ is $\mathrm{CO}_{2}$ emissions intensity of the steelmaking technology $r$ (tonne $\mathrm{CO}_{2}$ ), and $x_{t, i, r}$ represents the share of the production from the technology $r$ in year $t$ for pathway $i(\%)$. 
The $\mathrm{CO}_{2}$ emission intensity of the steel production $e_{r}$ is expressed as:

$$
e_{r}=\sum_{j} f_{j} s_{r, j}, \quad r \in R
$$

where $f_{j}$ denotes $\mathrm{CO}_{2}$ emission factor of fuel and reducing agent $j\left(\mathrm{~kg} \mathrm{CO}_{2} / \mathrm{kWh}\right), s_{r, j}$ is specific energy consumption of fuel and reducing agent $j$ in the technology $r(\mathrm{kWh} / \mathrm{t})$.

The steel production costs, $C_{r}^{T}$, for each of the steel production technologies $r$ are calculated as:

$$
C_{r}^{T}=V_{r}+F_{r}+A_{r}, \quad r \in R
$$

where $V_{r}$ is the variable operating cost, $F_{r}$ is the fixed operating costs and $A_{r}$ is the annualized capital costs which are calculated as:

$$
A_{r}=\frac{\operatorname{CAPEX}_{r}(1+i)^{n} i}{(1+i)^{n}-1}, t \in T, r \in R
$$

where $i$ is the interest rate assumed to be $5 \%, n$ is the economic lifetime assumed to be 20 years and $C A P E X_{r}$ is the capital cost of the steel production technologies $r$.

\subsection{Sensitivity Analysis}

Several European steel production companies have announced a transition towards electrification of steel production [26,41-43]. The level of the steel decarbonization from electrification option relies heavily on the level to which the electricity grid is decarbonized. Sweden already has a low $\mathrm{CO}_{2}$ emission grid factor compared to other countries. Therefore, a sensitivity analysis is performed for the carbon dioxide intensity of steel production via the H-DR/EAF process used in Pathway 2, 3 by varying $\mathrm{CO}_{2}$ emission grid factors. The results are compared to the $\mathrm{CO}_{2}$ intensity of the TGRBF/CCS/Biomass process used in Pathway 1 to estimate mitigation potential and feasible implementation time of these processes depending on $\mathrm{CO}_{2}$ emission grid factors. The sensitivity of $\mathrm{CO}_{2}$ emissions in steelmaking processes to the $\mathrm{CO}_{2}$ emission grid factor is calculated based on Equation (2) by applying future European $\mathrm{CO}_{2}$ emission grid factors estimated by the International Energy Agency (IEA) [44] (and given in Table A1). The IEA projection is done based on Sustainable Development Scenario [45], which is aligned with the Paris Agreement of limiting global temperatures to well below $2{ }^{\circ} \mathrm{C}$. The estimates of carbon dioxide emission per tonne of steel produced are done for the period 2020-2040 to identify when in Europe deep emission reduction via hydrogen direct reduction steelmaking should take place in order to meet targets.

\section{Results}

This section first presents the three pathways in terms of the development of energy consumption over time and comparison of the total steel production cost. This is followed by the of $\mathrm{CO}_{2}$ emissions along the pathways. Finally, the results of the sensitivity analysis are discussed.

\subsection{Future Productivity-Outline of Pathways}

Figure 2 gives the three production pathways for the Swedish steel industry showing the timing of replacement of current technology.

Pathway 1 (Figure 2a) represents a shift to the top gas recycling blast furnace with carbon capture and biomass for the conventional primary steel production and to the EAF with biomass for secondary steel production. From 2025, the total production level of BF/BOF equals $2.1 \mathrm{Mt} /$ year (42\% of the total steel production in Sweden) due to the blast furnace shutdown in Oxelösund and replacing it by the EAF (SSAB, 2018). By the year 2030 the current primary steel production technology is replaced by a 
combination of TGRBF and CCS technologies and the replacement of the coal for PCI with biomass. As regards $\mathrm{CO}_{2}$ capture technology, post-combustion technology is assumed.

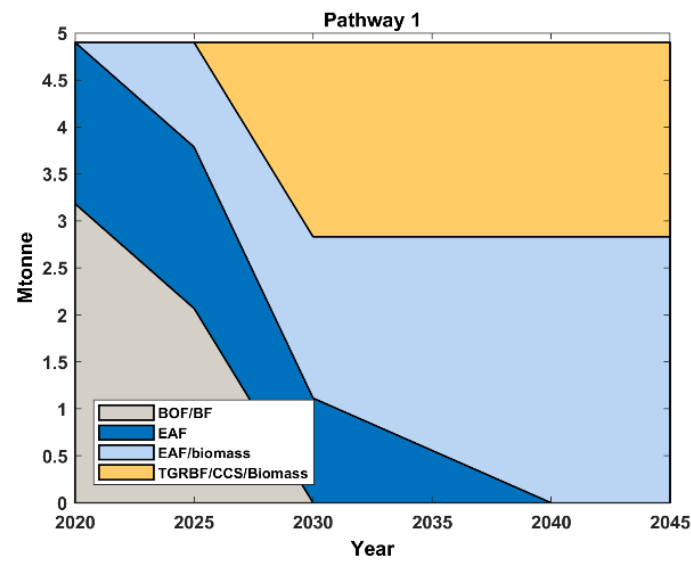

(a)

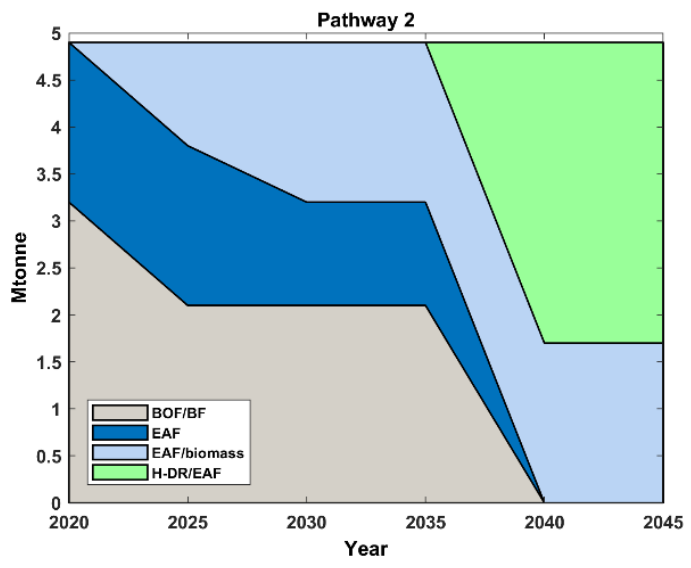

(b)

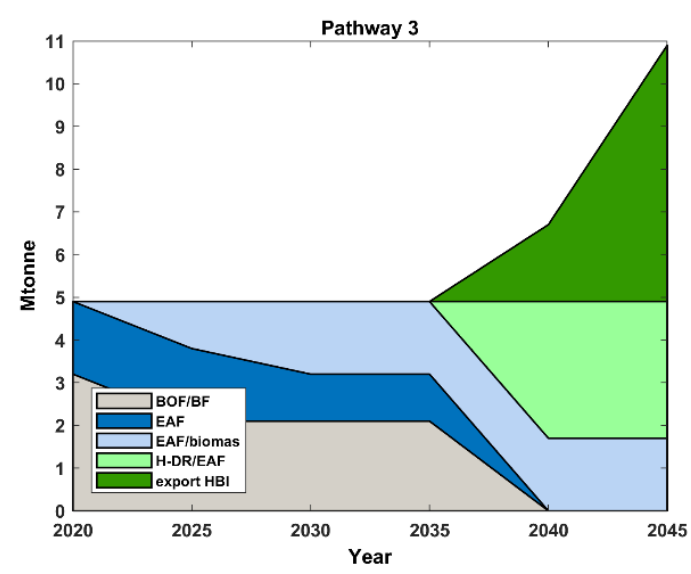

(c)

Figure 2. Production processes mix for the Swedish steel industry in Pathway 1 (a), Pathway 2 (b) and Pathway 3 (c) from 2020 to 2045. Note the different scale of the y-axis of Figure 2c.

In Pathways 2 and 3 (Figure 2b,c), Sweden's two blast furnaces are replaced by the hydrogen direct reduction (H-DR/EAF) steelmaking process, which is assumed to be implemented by 2040 (HYBRIT, 2016). Between 2025 and 2040, steel production is assumed to be done by the EAF with biomass at a level corresponding to about $58 \%$ of the current total production, which is due to the retirement of one blast furnace in 2025 .

For Pathway 3 (Figure 2c), the export of iron ore pellets is assumed to be replaced by the export of hot briquetted iron (HBI) pellets from 2040. The increased production of HBI in Sweden can replace current iron making in other regions and consequently lead to a reduction of $\mathrm{CO}_{2}$ emissions from ironmaking.

\subsection{Energy and Fuel Demand}

Figure 3 shows energy consumption for both primary and secondary steelmaking technologies. In Pathways 1, 2 and 3 (Figure 3a-c), the replacement of the iron ore-based steel plant with an EAF results in a coal consumption reduction in 2025. In Pathway 1 (Figure 3a), further coal demand decline is observed in 2030 since the injected pulverized coal into the blast furnace is replaced by biomass. 
Due to the reinjection of the top gas components $\mathrm{CO}$ and $\mathrm{H}_{2}$ to the blast furnace as a reducing agent of iron ore, total coke consumption for primary steel production in Pathway 1 is lowered by $27 \%$ compared to the conventional BF. In 2030, an increase in natural gas consumption by $44 \%$ is observed compared to current steel industry configuration, despite the reduction in natural gas consumption using biomass in EAFs. In the TGRBF/CCS, natural gas is utilized for the preheating of the steam, as well as for the supplemental thermal energy demand of the CCS technology [29].

For Pathway 2 (Figure 3b), the demand for fossil fuel-based energy carriers, such as coke, coal, oil and natural gas, decreases by almost 100\% in 2040 compared to the demand with current steel process configuration, due to the transition to the hydrogen direct reduction technology. However, from 2025 to 2040 the demand for fossil fuel-based energy carries is higher compared to Pathway 1 . The electricity use increases significantly, implying an electricity need of around 12 TWh per year in 2045. For Pathway 3 (Figure 3c), the energy consumption level is similar to Pathway 2 until 2040 when the electricity consumption increases dramatically to reach a level of 33 TWh per year in the year 2045.

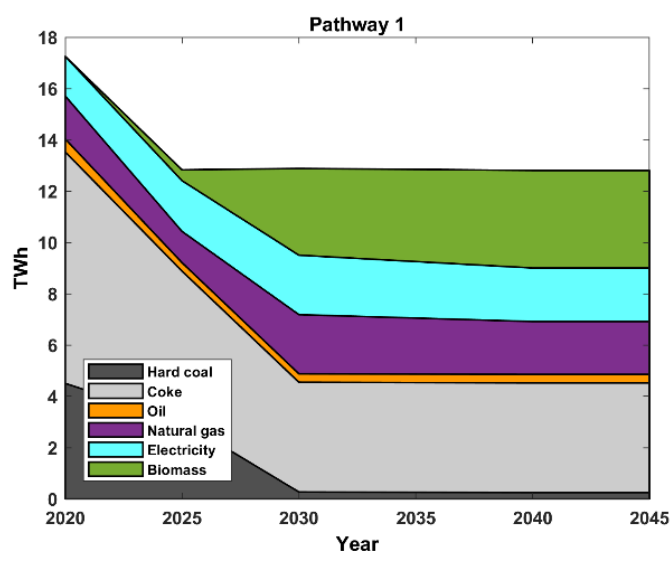

(a)

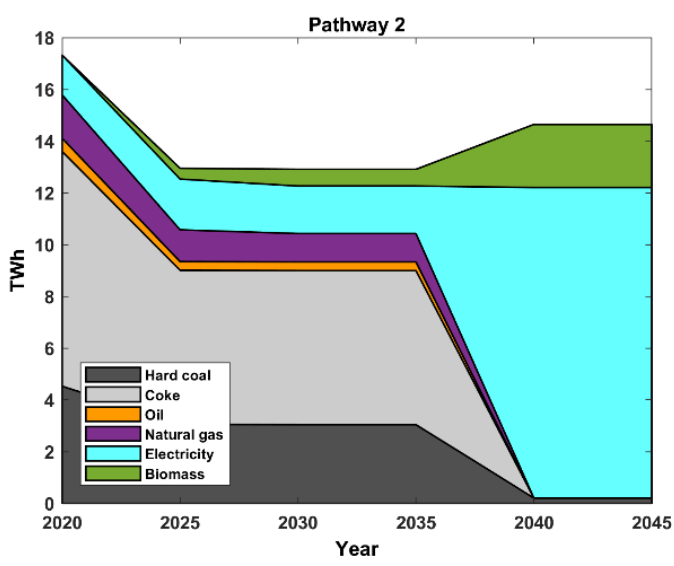

(b)

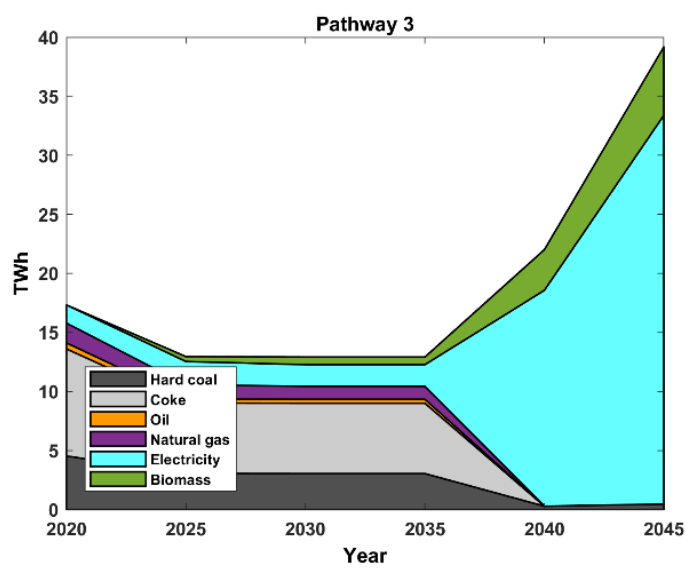

(c)

Figure 3. Energy use for the Swedish steel industry in Pathway 1 (a), Pathway 2 (b) and Pathway 3 (c) from 2020 to 2045. Note the different scale of the y-axis of Figure 3c.

\subsection{Steel Production Costs}

Figure 4 shows the production costs (Equation (4)) of 1 tonne of steel from primary and secondary steelmaking technologies applied in the investigated pathways, where capital expenditure (CAPEX) for the steel production technologies calculated as annuity payments (cf. Equation (5)). Nearly 60\% 
of current steel production costs consist of raw materials (i.e., iron ore, ferroalloys, scrap and fluxes), fuels and reductant, while CAPEX only contributes to around $20 \%$ of the total cost. Thus, since steel production costs are strongly influenced by different market drivers, mainly raw material cost and energy prices, which vary from location to location, the production cost figures obtained are indicative. Figure 4a shows steel production cost for primary steelmaking via the conventional process $(\mathrm{BF} / \mathrm{BOF})$, TGRBF/CCS with biomass (Pathway 1) and H-DR/EAF (Pathways 2,3), since the same primary steelmaking technology is used in Pathways 2 and 3, the production costs for these pathways are the same. As for secondary steelmaking, conventional EAF is compared to EAF with biomass implemented in Pathways 1-3 (Figure 4b).

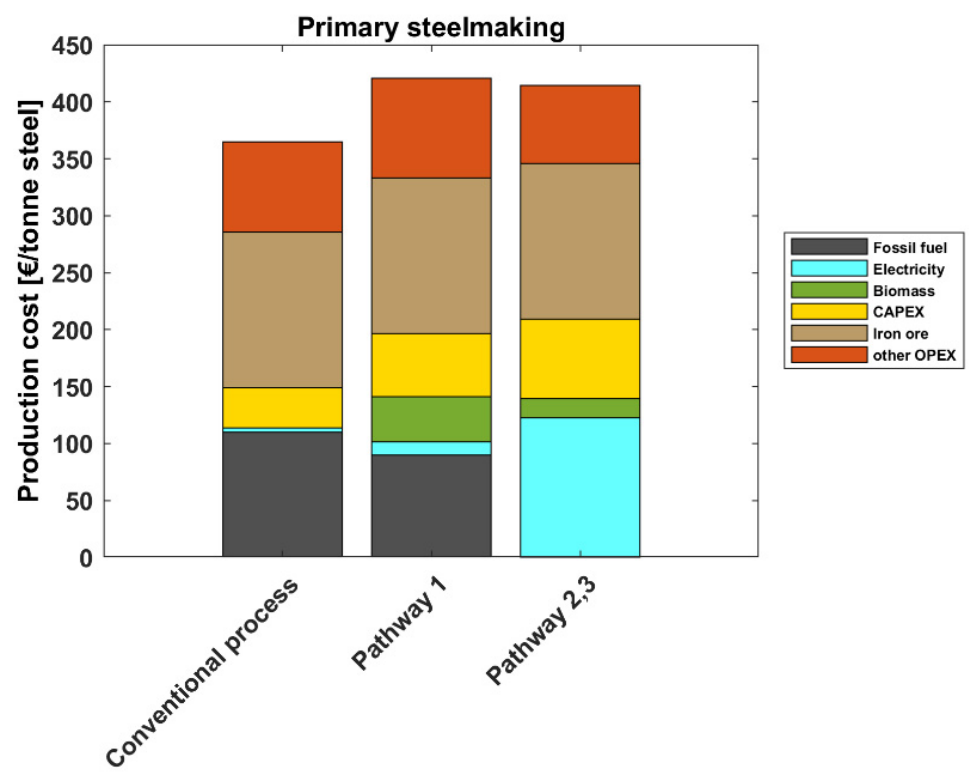

(a)

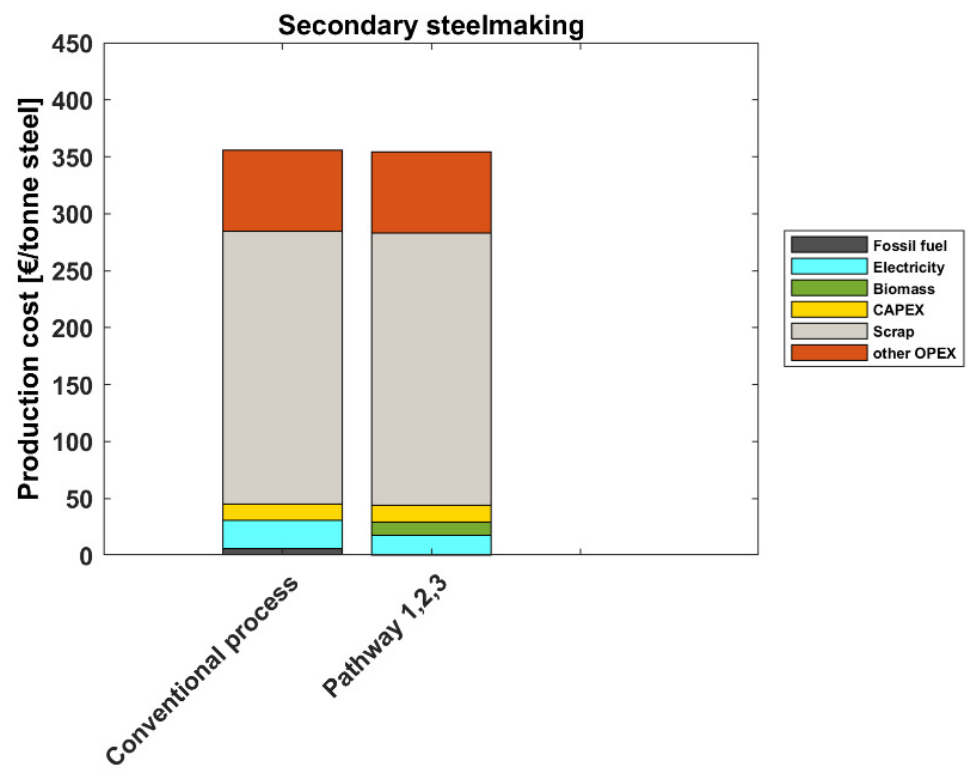

(b)

Figure 4. Steel production cost for primary steelmaking technologies (a) and secondary steelmaking technologies (b) applied in the pathways investigated in this work. 
Primary steelmaking with $\mathrm{CO}_{2}$ emissions reduction, such as applied in Pathways 1-3, implies steel production cost increase by $12-13 \%$ compared to conventional primary steelmaking. Capital expenditures for Pathway 1 and Pathways 2, 3 increase by 55\% and 97\%, respectively, compared to capital expenditures for the conventional process. The cost of electricity is the dominant cost for Pathways 2 and 3 and makes up 30\% of total production cost. In this work, an average electricity price for Sweden between 2012 and 2019 of 35 EUR per MWh is used and it is assumed this electricity price level remains constant up to 2045. This, since little is known about the future costs of electricity, but cost can be reduced due to increased share of renewables. Yet, in order to achieve this electricity price level, there is flexible operation of the electrolyser so that periods of high electricity prices are avoided, is likely required. However, such operation strongly depends on electricity system composition and might lead to additional capital expenses of hydrogen storage and electrolyser capacities. Based on our assumptions, secondary steelmaking using EAF, where coke and natural gas are replaced with biomass, offers production cost similar to conventional EAF (Figure 4b).

Figure 5 shows the development of the average steel production cost over time for investigated pathways. Pathways 2 and 3 have identical production cost development, since the same steelmaking technologies are invested in along these pathways. All three pathways show a slight increase in production cost due to investments and increased fuel prices. The production cost in Pathway 1 increases by $5 \%$ in 2030 and by $8 \%$ in 2040 compared to the current production cost due to the investments in new production technology. The average steel production cost in Pathway 2 is relatively stable up to 2040. From 2040, the steel production cost of Pathway 2 is $16 \%$ higher compared to the 2020 cost.

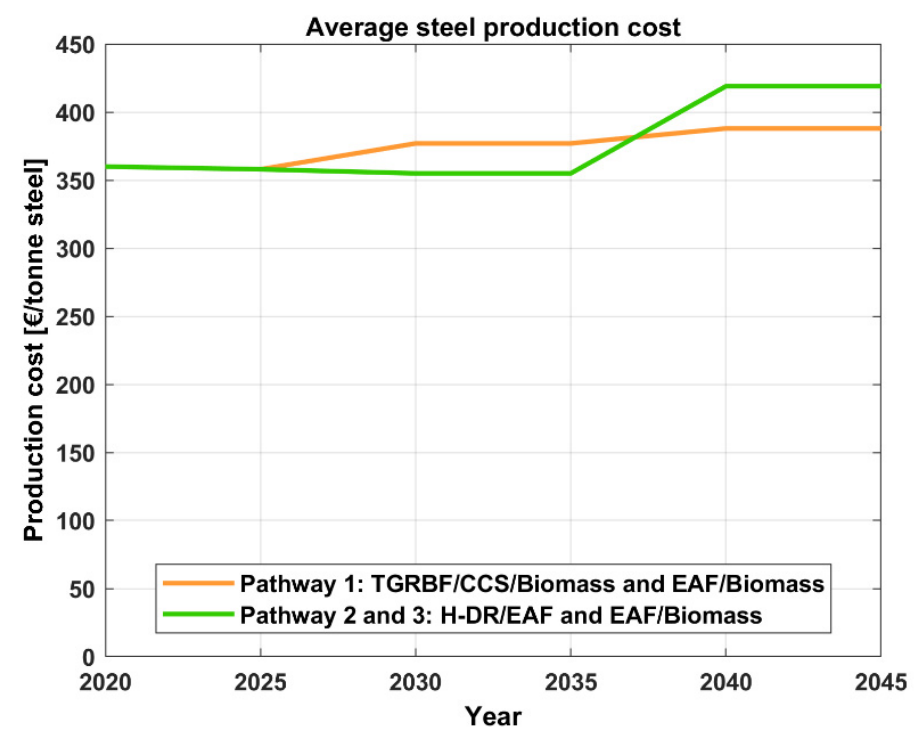

Figure 5. Development of the average steel production cost for the three pathways investigated.

\subsection{The Pathways in Relation to the $\mathrm{CO}_{2}$ Emission Targets}

Figure 6 shows the development of the $\mathrm{CO}_{2}$ emission intensity of steel production for the three pathways. Steel production via processes with substantial electricity demand, such as H-DR/EAF (Pathways 2,3) and EAF (Pathways 1-3), results in low $\mathrm{CO}_{2}$ intensity of steel production due to the low $\mathrm{CO}_{2}$ emission grid factor of the Swedish electricity system. For primary steelmaking in Pathway 1 , the decrease in the $\mathrm{CO}_{2}$ emission grid factor between 2030 and 2045 results in the reduction of steel $\mathrm{CO}_{2}$ intensity only by $2 \%$. 


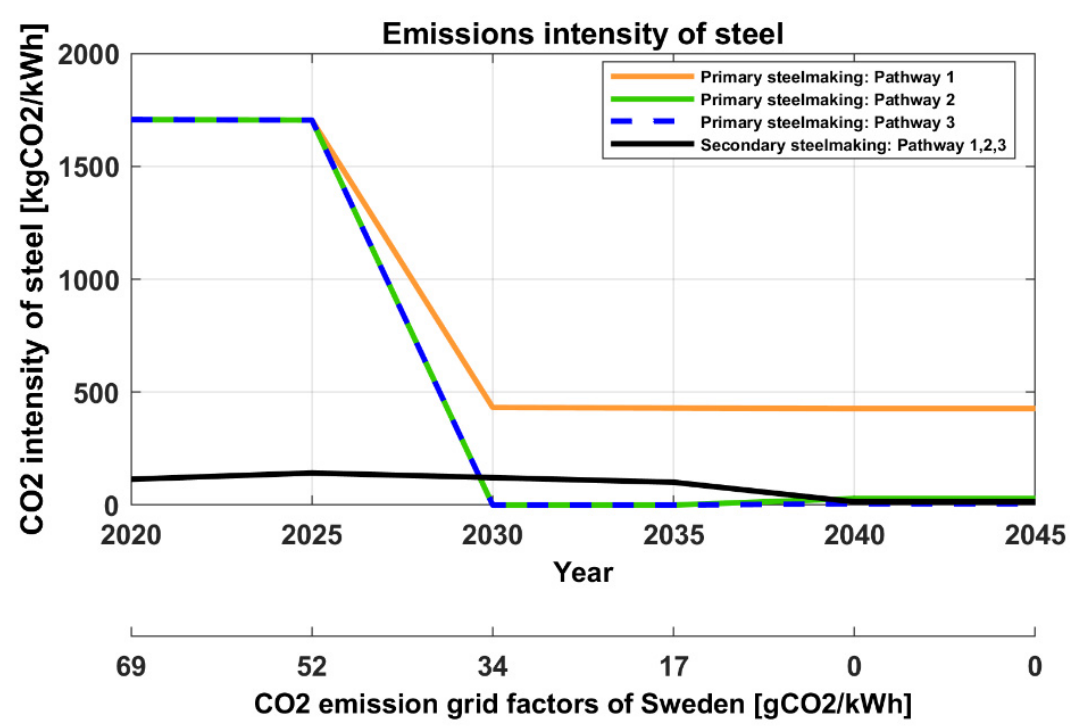

Figure 6. Development of $\mathrm{CO}_{2}$ emission intensity of the steel production (primary and secondary steelmaking) for the three pathways.

Figure 7 shows the development of $\mathrm{CO}_{2}$ emissions over time for the Swedish steel industry for the three pathways. As shown in Figure 7, Pathway 1 yields up of $83 \%$ emissions reduction in 2045 , i.e., applying CCS in combination with biomass substitution in the blast furnace as well as a replacement iron ore-based steel plant with an EAF. Furthermore, already in 2030, an 80\% reduction in $\mathrm{CO}_{2}$ emissions is obtained. Pathways 2 and 3, including electrification, enable further emission reductions compared to implementing CCS and utilization of biomass. As can be seen in Figure 7, none of the pathways can achieve zero $\mathrm{CO}_{2}$ emissions due to emissions emerging in lime production and the addition of carbon to make steel, which is an essential component in steelmaking.

From 2040, there is a slight increase in $\mathrm{CO}_{2}$ emissions for Pathway 3 resulting from the large growth in HBI pellet production for export, which could support international emissions reduction efforts not accounted for here.

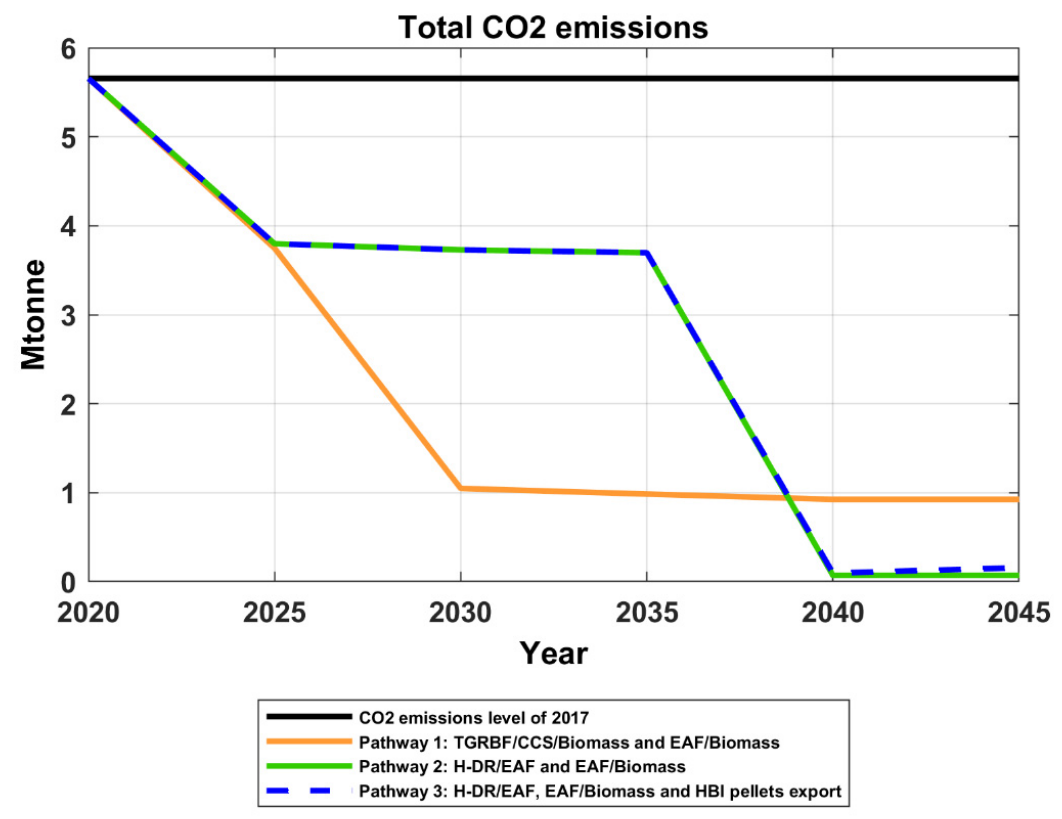

Figure 7. Development of $\mathrm{CO}_{2}$ emissions for the Swedish steel industry pathways from 2020 to 2045. 


\subsection{Sensitivity Analysis}

Figure 8 illustrates the results of the $\mathrm{CO}_{2}$ emission intensity of the primary steelmaking processes applied in Pathways 1 and 2, depending on the $\mathrm{CO}_{2}$ emission grid factors, including the timeline for the European electricity mix as estimated by IEA. The right y-axis shows the timing of future European $\mathrm{CO}_{2}$ emission grid factors estimated by IEA [44]. For future European $\mathrm{CO}_{2}$ emission grid factor using CCS in combination with biomass substitution in the blast furnace provides higher $\mathrm{CO}_{2}$ emissions reduction potential compared to hydrogen direct reduction steelmaking up until 2025. With given future European emission grid factors, the hydrogen direct reduction (H-DR/EAF) steelmaking process allows the reduction of emissions from conventional steel production by $50 \%$ in 2020, however, already in 2030, this option provides the greatest $\mathrm{CO}_{2}$ emissions reduction potential compared to investigated abatement measures for primary steelmaking. The complexity of the plant infrastructure is one of the central issues in capturing $\mathrm{CO}_{2}$ from steel production. Carbon dioxide emissions are distributed over a large area from different point sources (the lime kilns, sinter plants, coke ovens, hot stoves, BF, and BOF) with potentially different emission rates and flue gas compositions. Since in this study we assumed TGRBF as a capture point, it is not possible to reach near-zero emissions from primary steelmaking in Pathway 1. Applying CCS to all stacks in an integrated steel plant is possible in theory and would lead to near-zero $\mathrm{CO}_{2}$ emissions. It should be mentioned that the current $\mathrm{Swedish} \mathrm{CO}_{2}$ emission grid factor is $69 \mathrm{~g} \mathrm{CO}_{2} / \mathrm{kWh}$ which would make hydrogen direct reduction the best solution to cut $\mathrm{CO}_{2}$ emission from steelmaking deeply already at the present electricity production mix. The sensitivity analysis shows that the decarbonization of electricity supply is decisive for achieving near zero $\mathrm{CO}_{2}$ emission cuts in the steel industry.

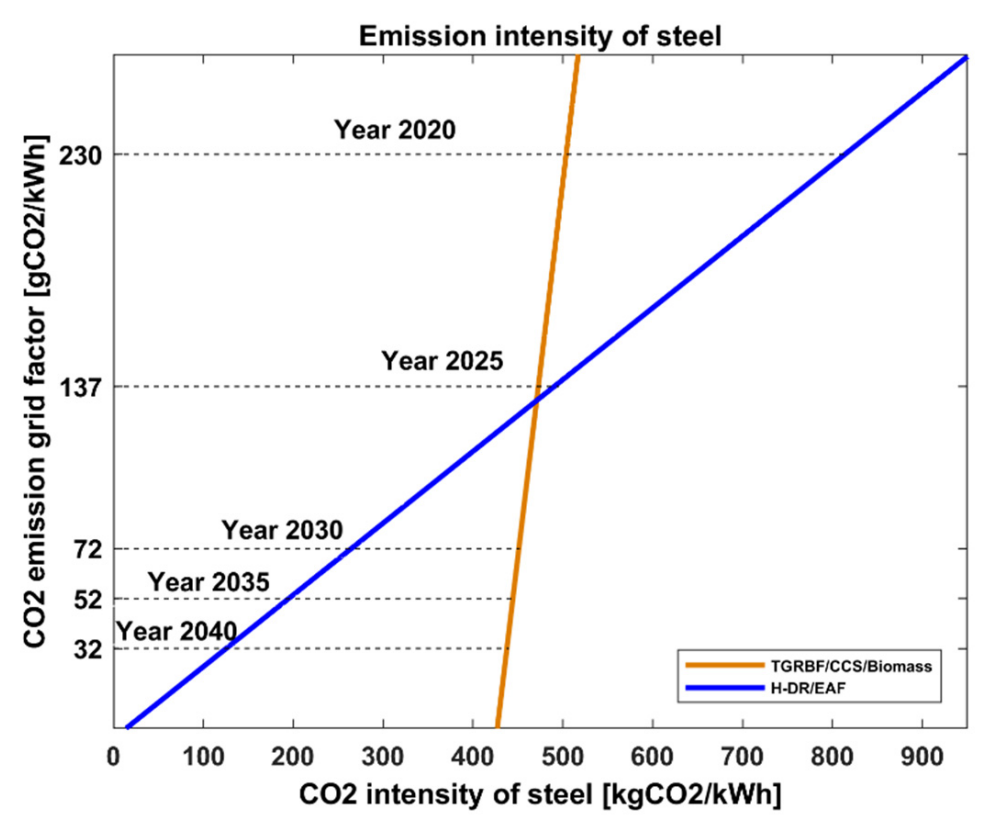

Figure 8. $\mathrm{CO}_{2}$ emissions intensity of primary steelmaking in Pathway 1 (orange) and Pathways 2, 3 (blue) as function of future European $\mathrm{CO}_{2}$ emission grid factor. The horizontal dotted lines indicate the development of the European $\mathrm{CO}_{2}$ emission grid factors as estimated by IEA [44].

\section{Discussion}

The aim of this study was to explore how different choices, with respect to technological development in the Swedish steel industry, impact energy use, $\mathrm{CO}_{2}$ emissions and cost over time. However, it should be noted that the steel production pathways assessed in this study are exploratory and not intended as projections. 
It should also be pointed out that this study does not consider the variation of scrap availability and demand in the investigated pathways. For all investigated alternative pathways scrap consumption should increase from 2025 due to replacement BF/BOF by EAF. A global increase in scrap availability due to stocks building up in emerging economies is expected [46] while the availability in the EU will stabilize, as steel stock saturates [47]. In addition, it is important to prioritize innovation and technological development related to delivering the highest quality of steel from recycling (EAF) (see e.g., [48]).

Furthermore, the uncertainty of the steel production cost results obtained in this study may be larger than quantified by our analysis. The primary steelmaking process in Pathways 2, 3, hydrogen direct reduction, allows for flexible operation of the steel plant. The flexibility in the steelmaking process benefits form periods of low electricity price, and this becomes particularly important for electricity systems with a high share of variable renewables. However, it also brings investments in storage technologies and additional investments in production capacities (electrolyzer, direct reduction shaft, EAF). This study did not assess these consequences of flexibility. Furthermore, the introduction of the carbon price, by means of carbon credits and/or carbon tax can be estimated to increase the competitiveness of steel production via alternative processes (Pathways 1-3). Feliciano-Bruzual C. [49], shows that the price of carbon emission in the range of 40-190€/t $\mathrm{CO}_{2}$ could make charcoal substitution economically competitive.

Finally, in two of the pathways the study assumed Swedish steel production will remain constant at the 2017 level until 2045. Steel is a globally traded good and steel demand internationally is affected by several factors, e.g., state of the global economy, and therefore development in a region, such as the Swedish steel industry, is difficult to predict. However, change of future demand and production levels obviously will have major impacts on the results for energy use and $\mathrm{CO}_{2}$ emissions.

Only a relatively small share of the steel produced in Sweden has a domestic end-use, i.e., most $(>85 \%)$ of the steel produced in Sweden is exported. Still, even though mitigating $\mathrm{CO}_{2}$ emission by using less steel has a limited potential on national basis such efforts will: (i) limit the use of steel; (ii) maximize upgrading, recycling and reuse of steel already in use; (iii) switch to lower- $\mathrm{CO}_{2}$ materials; and (iv) use less steel for same function. These aspects will be important to decrease carbon dioxide emissions related to steel production and to reach the long-term emission reduction goals.

Steelmaking firms seeking to invest in high-cost high-risk (but low- $\mathrm{CO}_{2}$ ) technology face a dilemma. On the one hand, it is difficult to motivate and find a business case for investments away from traditional and established technologies, especially in the currently uncertain policy regime, on the other hand, a failure to invest in a shift to less carbon-intensive technology is incompatible with the Paris Agreement. Thus, it is worth pointing out, which is also done in other work [4], that a current policy mix targeting the basic material industry will need to be accompanied by complementary policy interventions and/or private initiatives to secure financing and lower the financial risk in investments for decarbonization up to 2045.

\section{Conclusions}

This paper explores pathways for deep $\mathrm{CO}_{2}$ emission cuts in the Swedish steel industry up to 2045, with respect to technological development, energy use, carbon dioxide emissions and cost over time. The alternative pathways, e.g., TGRBF with CCS and biomass, H-DR/EAF and EAF/biomass, are compared to the current (2017) Swedish steelmaking technologies.

The technological assessment has shown that in 2030, it should be reasonable to assume that $\mathrm{CO}_{2}$ emission reductions of $80 \%$ compared to current process configurations can be achieved applying TGRBF/CCS with biomass along with electric arc furnace with biomass as $\mathrm{CO}_{2}$ mitigation options. Using biomass instead of PCI for the primary steelmaking process, would result in a biomass demand from the steel industry in 2045 equal to $6 \%$ of the current total current biomass consumption in Sweden. At present, biomass is hardly used at all in the steel industry. Even though there is potential for increased utilization of biomass instead of PCI in the Swedish steel industry in the mid to long term [50], 
the available biomass is subject to competition, since other sectors are also aiming to increase their use of biomass to achieve their emission reduction goals.

Pathway 2 shows that electrification of primary steel production, in terms of using hydrogen as a reducing agent in $\mathrm{H}-\mathrm{DR} / \mathrm{EAF}$ technology, can result in a 10\% reduction in total Swedish carbon dioxide emissions. The main challenge of the electrification in Pathway 2 is the resulting electricity demand of almost 14 TWh in 2045.

The results from this work suggest that the increased production of HBI pellets, as assumed in Pathway 3, can lead to reduction in $\mathrm{CO}_{2}$ emissions from the steel industry outside Sweden, assuming that the exported HBI will be converted via EAF and the receiving country has a decarbonized power sector. Such a pathway leads to new investments in Swedish steel production capacities and an additional electricity demand of 25.6 TWh (current electricity demand of steel industry is 7.4 TWh).

Author Contributions: Conceptualization, A.T., L.G. and F.J.; methodology: A.T., L.G. and F.J.; software, A.T.; validation: A.T.; formal analysis, A.T., I.K. and J.R.; investigation, A.T. and I.K.; resources, A.T., data curation: A.T.; writing - original draft preparation, A.T.; writing - review and editing, A.T., L.G., I.K, J.R., M.O. and F.J; visualization, A.T.; project administration, F.J. and M.O.; funding acquisition, F.J. All authors have read and agreed to the published version of the manuscript.

Funding: This work was financed by the Mistra Carbon Exit Research programme.

Acknowledgments: Financial support from Mistra is gratefully acknowledged.

Conflicts of Interest: The authors declare no conflict of interest.

\section{Appendix A}

Table A1. Specific energy consumption per tonne of steel, $\mathrm{CO}_{2}$ emission factors and price of reducing agent and fuel mix applied in the investigated pathways.

\begin{tabular}{|c|c|c|c|c|c|c|c|}
\hline \multirow{3}{*}{$\begin{array}{c}\text { Specific } \\
\text { Energy Input, } \\
\text { kWh/Tonne }\end{array}$} & \multicolumn{3}{|c|}{ Primary Steelmaking } & \multicolumn{2}{|c|}{ Secondary Steelmaking } & \multirow{3}{*}{$\begin{array}{c}\mathrm{CO}_{2} \\
\text { Intensity } \\
\text { Factor, kg } \\
\mathrm{CO}_{2} / \mathrm{kWh}^{4}\end{array}$} & \multirow{3}{*}{$\begin{array}{c}\text { Reducing } \\
\text { Agent/Fuel } \\
\text { Mix Price, } \\
\text { €/MWh }{ }^{5}\end{array}$} \\
\hline & Conventional & Pathway 1 & Pathway 2,3 & Conventional & Pathway $1,2,3$ & & \\
\hline & BF/BOF ${ }^{1}$ & $\begin{array}{c}\text { TGRBF } \\
+ \text { CCS/Biomass }{ }^{2}\end{array}$ & H-DR/EAF ${ }^{3}$ & EAF $^{1}$ & $\underset{\text { Biomass }^{3}}{\text { EAF + }}$ & & \\
\hline Biomass & 0 & 1319 & 560 & 0 & 380 & 0 & 30 \\
\hline Coke & 2835 & 2067 & 0 & 0 & 0 & 0.385 & 28 \\
\hline Electricity & 108 & 333 & 3488 & 700 & 494 & var & 35 \\
\hline Oil & 159 & 159 & 0 & 0 & 0 & 0.277 & 42 \\
\hline
\end{tabular}

${ }^{1}$ All values are from [51]. ${ }^{2}$ All values are from [18], except for biomass and oil consumption values. The biomass consumption value is assumed based on [34]. The oil consumption value is from [51]. ${ }^{3}$ All values are from [37]. ${ }^{4}$ All values from [52], The grid $\mathrm{CO}_{2}$ emission factor depends on the year (Table A1). ${ }^{5}$ All values are from [53], except for biomass price, electricity price and coke price. The biomass price is from [54], average electricity price for years 2012-2019 is from [55], and coke price is from [56].

Table A2. $\mathrm{CO}_{2}$ emission grid factor of Sweden and Europe for the years 2020-2040.

\begin{tabular}{ccc}
\hline $\mathbf{C O}_{\mathbf{2}}$ Emission Grid Factor, $\mathbf{g ~ C O}_{\mathbf{2}} \mathbf{/ k W h}$ & Sweden $^{\mathbf{1}}$ & European Union $^{\mathbf{2}}$ \\
\hline 2020 & $69^{2}$ & 230 \\
2025 & 52 & 137 \\
2030 & 34 & 72 \\
2035 & 17 & 52 \\
2040 & 0 & 32
\end{tabular}

\footnotetext{
${ }^{1}$ Own calculations. The $\mathrm{CO}_{2}$ emission grid factor for Year 2020 is assumed to be equal $\mathrm{CO}_{2}$ emission grid of 2017.

${ }^{2}$ All values are from [44].
} 
Table A3. Capital and operating expenses of steelmaking technologies for investigated pathways.

\begin{tabular}{cccccc}
\hline & \multicolumn{3}{c}{ Primary Steelmaking } & \multicolumn{2}{c}{ Secondary Steelmaking } \\
\cline { 2 - 6 } & Conventional & Pathway $\mathbf{1}$ & Pathway 2,3 & Conventional & Pathway 1,2,3 \\
\cline { 2 - 6 } & BF/BOF & $\begin{array}{c}\text { TGRBF + } \\
\text { CCS/Biomass }\end{array}$ & H-DR/EAF & EAF & $\begin{array}{c}\text { EAF + } \\
\text { Biomass }\end{array}$ \\
\hline CAPEX, $€ /$ tonne & $442^{1}$ & $692^{2}$ & $874^{3}$ & $184^{1}$ & $184^{4}$ \\
\hline Total OPEX, $€ /$ tonne & 216 & 224 & 205 & 311 & 310 \\
\hline Iron ore, $€ /$ tonne $^{5}$ & 136 & 136 & 136 & & 239 \\
\hline Scrap, $€ /$ tonne $^{6}$ & & & & 72 & 71 \\
\hline Other OPEX, $€ /$ tonne $^{1}$ & 80 & 88 & 69 & 239 & 72 \\
\hline
\end{tabular}

${ }^{1}$ Values are from [16]. ${ }^{2}$ Value is based on [19,21]. ${ }^{3}$ Value is from [9]. Hydrogen storage capacity is assumed for 14 days with CAPEX $0.09 € / \mathrm{kWh} .{ }^{4}$ Value is assumed to be equal to the CAPEX of the conventional EAF. ${ }^{5}$ Iron ore demand is from [51] and iron ore price is from [53]. ${ }^{6}$ Scrap demand is from [51] and scrap price is from [56].

\section{References}

1. SCB Greenhouse Gas Emissions and Removals. Available online: https://www.scb.se/en/finding-statistics/ statistics-by-subject-area/environment/emissions/greenhouse-gas-emissions-and-removals/ (accessed on 17 June 2020).

2. Ministry of the Environment and Energy. The Swedish Climate Policy Framework; Ministry of the Environment and Energy: Stockholm, Sweden, 2018.

3. Ballester, C.; Furió, D. Effects of renewables on the stylized facts of electricity prices. Renew. Sustain. Energy Rev. 2015, 52, 1596-1609. [CrossRef]

4. Bataille, C.; Åhman, M.; Neuhoff, K.; Nilsson, L.J.; Fischedick, M.; Lechtenböhmer, S.; Solano-Rodriquez, B.; Denis-Ryan, A.; Stiebert, S.; Waisman, H.; et al. A review of technology and policy deep decarbonization pathway options for making energy-intensive industry production consistent with the Paris Agreement. J. Clean. Prod. 2018, 187, 960-973. [CrossRef]

5. Johansson, M.T.; Söderström, M. Options for the Swedish steel industry-Energy efficiency measures and fuel conversion. Energy 2011, 36, 191-198. [CrossRef]

6. Wang, C.; Mellin, P.; Lövgren, J.; Nilsson, L.; Yang, W.; Salman, H.; Hultgren, A.; Larsson, M. Biomass as blast furnace injectant-Considering availability, pretreatment and deployment in the Swedish steel industry. Energy Convers. Manag. 2015, 102, 217-226. [CrossRef]

7. Mandova, H.; Patrizio, P.; Leduc, S.; Kjärstad, J.; Wang, C.; Wetterlund, E.; Kraxner, F.; Gale, W. Achieving carbon-neutral iron and steelmaking in Europe through the deployment of bioenergy with carbon capture and storage. J. Clean. Prod. 2019, 218, 118-129. [CrossRef]

8. Lechtenböhmer, S.; Nilsson, L.J.; Åhman, M.; Schneider, C. Decarbonising the energy intensive basic materials industry through electrification-Implications for future EU electricity demand. Energy 2016, 115, 1623-1631. [CrossRef]

9. Fischedick, M.; Marzinkowski, J.; Winzer, P.; Weigel, M. Techno-economic evaluation of innovative steel production technologies. J. Clean. Prod. 2014, 84, 563-580. [CrossRef]

10. Arens, M.; Worrell, E.; Eichhammer, W.; Hasanbeigi, A.; Zhang, Q. Pathways to a low-carbon iron and steel industry in the medium-term-the case of Germany. J. Clean. Prod. 2017, 163, 84-98. [CrossRef]

11. LKAB. Annual and Sustainability Report; LKAB: Luleå, Sweden, 2017.

12. Jernkontoret Companies and Plants. Available online: https://www.jernkontoret.se/en/the-steel-industry/ companies-and-plants/ (accessed on 17 June 2020).

13. SSAB First in Fossil-Free Steel. Available online: https://www.ssab.com/company/sustainability/sustainableoperations/hybrit (accessed on 17 June 2020).

14. Klar, D.; Frishammar, J.; Roman, V.; Hallberg, D. A Technology Readiness Level scale for iron and steel industries. Ironmak. Steelmak. 2016, 43, 494-499. [CrossRef]

15. Association, E.E.S. A Steel Roadmap for a Low Carbon Europe 2050; The Boston Consulting Group (BCG): Boston, MA, USA, 2013. 
16. Wörtler, M.; Schuler, F.; Voigt, N.; Schmidt, T.; Dahlmann, P.; Lüngen, H.B.; Ghenda, J.-T. Steel's contribution to a low-carbon Europe 2050: Technical and economic analysis of the sector's $\mathrm{CO}_{2}$ abatement potential. Lond. BCG Retrieved April 2013, 20, 2015.

17. Carpenter, A. $\mathrm{CO}_{2}$ abatement in the iron and steel industry. IEA Clean Coal Cent. 2012, 67-70.

18. GHG, I. IEAGHG Iron and Steel CCS Study (Techno-Economics Integrated Steel Mill); IEA: Paris, France, 2013.

19. Lee, S.; Pollitt, H.; Fujikawa, K. Energy, Environmental and Economic Sustainability in East Asia: Policies and Institutional Reforms; Routledge: Abingdon, UK, 2019.

20. Haines, M.; Kemper, J.; Davison, J.; Gale, J.; Singh, P.; Santos, S. Assessment of Emerging CO 2 Capture Technologies and Their Potential to Reduce Costs; International Energy Agency (IEA): Paris, France, 2014.

21. Kuramochi, T.; Ramírez, A.; Turkenburg, W.; Faaij, A. Comparative assessment of $\mathrm{CO}_{2}$ capture technologies for carbon-intensive industrial processes. Prog. Energy Combust. Sci. 2012, 38, 87-112. [CrossRef]

22. Torp, T.A. Drastic Reduction of $\mathrm{CO}_{2}$ Emissions from Steel Production with $\mathrm{CO}_{2}$ Capture and Storage (CCS)_ULCOS Project. In Proceedings of the Technical Committee Meeting, Rome, Italy, 27 June 2005.

23. McKinsey, C. Pathways to a Low Carbon Economy - Version 2 of the Global Greenhouse Gas Abatement Cost Curve; McKinsey Company: New York, NY, USA, 2009.

24. Kirschen, M.; Badr, K.; Pfeifer, H. Influence of direct reduced iron on the energy balance of the electric arc furnace in steel industry. Energy 2011, 36, 6146-6155. [CrossRef]

25. Axelson, M.; Robson, I.; Wyns, T.; Khandekar, G. Breaking Through-Industrial Low-CO 2 Technologies on the Horizon; Institute for European Studies, Vrije Universiteit Brussel: Bruxelles, Belgium, 2018.

26. LKAB; SSAB. Vattenfall Fossil-Free Steel-Hybrit. Available online: http://www.hybritdevelopment.com/ (accessed on 5 April 2020).

27. Vogl, V.; Åhman, M.; Nilsson, L.J. Assessment of hydrogen direct reduction for fossil-free steelmaking. J. Clean. Prod. 2018, 203, 736-745. [CrossRef]

28. Siderwin Development of new methodologies for Industrial $\mathrm{CO}_{2}$-free steel production by electrowinning. Available online: https://www.siderwin-spire.eu/ (accessed on 17 June 2020).

29. Otto, A.; Robinius, M.; Grube, T.; Schiebahn, S.; Praktiknjo, A.; Stolten, D. Power-to-steel: Reducing $\mathrm{CO}_{2}$ through the integration of renewable energy and hydrogen into the German steel industry. Energies 2017, 10, 451. [CrossRef]

30. Xylia, M.; Silveira, S.; Duerinck, J.; Meinke-Hubeny, F. Weighing regional scrap availability in global pathways for steel production processes. Energy Effic. 2018, 11, 1135-1159. [CrossRef]

31. Bianco, L.; Baracchini, G.; Cirilli, F.; Di Sante, L.; Moriconi, A.; Moriconi, E.; Agorio, M.M.; Pfeifer, H.; Echterhof, T.; Demus, T. Sustainable electric arc furnace steel production: GREENEAF. BHM Berg-und Hüttenmännische Monatshefte 2013, 158, 17-23. [CrossRef]

32. Birat, J.P.; Maizière-lès-Metz, D. Steel Sectoral Report Contribution to the UNIDO Roadmap on CCS1-Fifth Draft JP; Arcelor Mittal Global R and D: Maizières-lès-Metz, France, 2010.

33. Adams, S.; Schnittger, S.; Kockar, I.; Kelly, N.; Xu, H.; Monari, F.; Edrah, M.; Zhang, J.; Bell, G. Impact of Electrolysers on the Network; Scottish \& Southern Electricity Networks: Perth, Scotland, 2016.

34. Mathieson, J.G.; Rogers, H.; Somerville, M.A.; Jahanshahi, S.; Ridgeway, P. Potential for the Use of Biomass in the Iron and Steel Industry. In Proceedings of the Chemeca 2011: Engineering a Better World: Sydney Hilton Hotel, NSW, Australia, 18-21 September 2011.

35. Borlée, J. Low $\mathrm{CO}_{2}$ Steels-ULCOS Project (Ultra Low $\mathrm{CO}_{2}$ Steelmaking). In Proceedings of the IEA Deployment Workshop, Paris, France, 8-9 October 2007; Volume 9.

36. Chunbao Charles, X.U.; Cang, D. A brief overview of low $\mathrm{CO}_{2}$ emission technologies for iron and steel making. J. Iron Steel Res. Int. 2010, 17, 1-7.

37. HYBRIT. HYBRIT-A Swedish Prefeasibility Study Project for Hydrogen Based $\mathrm{CO}_{2}$-Free Ironmaking; SSAB: Stockholm, Sweden, 2016.

38. Rosenbloom, D. Pathways: An emerging concept for the theory and governance of low-carbon transitions. Glob. Environ. Chang. 2017, 43, 37-50. [CrossRef]

39. Forum, O.E. Ocean energy strategic roadmap. Build. Ocean Energy Eur. 2016. Available online: https: //webgate.ec.europa.eu/maritimeforum/en/node/3962 (accessed on 22 July 2020).

40. IEA Key energy statistics. 2018. Available online: https://www.iea.org/countries/sweden (accessed on 17 June 2020). 
41. Arcelor Mittal. Arcelor Mittal Commissions Midrex to Design Demonstration Plant for Hydrogen Steel Production in Hamburg. Available online: https://corporate.arcelormittal.com/media/news-articles/2019sep-16-arcelormittal-commissions-midrex-to-design-demonstration-plant (accessed on 5 April 2020).

42. Salzgitter AG. Salzgitter AG und Tenova Unterzeichnen Absichtserklärung für das SALCOS-Projekt: $\mathrm{CO}_{2}$-Arme Stahlproduktion auf Wasserstoffbasis. Available online: https://www.salzgitter-ag.com/de/ newsroom/pressemeldungen/pressemeldung-der-salzgitter-ag/2019-04-03-1/salzgitter-ag-und-tenovaunterzeichnen-absichtserklrung-fr-das-salcosprojekt-co2arme-stahlproduktion-auf-wasserstoffbasis.html (accessed on 22 July 2020).

43. Voestalpine the Three Pillars of Decarbonization. Available online: https://www.voestalpine.com/blog/en/ innovation-en/the-three-pillars-of-decarbonization/ (accessed on 5 April 2020).

44. IEA Tracking Power. 2019. Available online: https://www.iea.org/reports/tracking-power-2019 (accessed on 24 June 2020).

45. IE World Energy Model. Scenario Analysis of Future Energy Trends. Available online: https://www.iea.org/ reports/world-energy-model/sustainable-development-scenario\#abstract (accessed on 24 June 2020).

46. Pauliuk, S.; Milford, R.L.; Müller, D.B.; Allwood, J.M. The steel scrap age. Environ. Sci. Technol. 2013, 47, 3448-3454. [CrossRef] [PubMed]

47. Consortium, E. Treating Waste as a Resource for the EU Industry: Analysis of Various Waste Streams and the Competitiveness of Their Client Industries; ECSIP Consortium: Rotterdam, The Netherlands, 2013.

48. Allwood, J.; Azevedo, J.; Clare, A.; Cleaver, C.; Cullen, J.; Dunant, C.F.; Fellin, T.; Hawkins, W.; Horrocks, I.; Horton, P. Absolute Zero: Delivering the UK's Climate Change Commitment with Incremental Changes to Today's Technologies; University of Cambridge: Cambridge, UK, 2019.

49. Feliciano-Bruzual, C. Charcoal injection in blast furnaces (Bio-PCI): $\mathrm{CO}_{2}$ reduction potential and economic prospects. J. Mater. Res. Technol. 2014. [CrossRef]

50. Mellin, P.; Wei, W.; Yang, W.; Salman, H.; Hultgren, A.; Wang, C. Biomass availability in Sweden for use in blast furnaces. Energy Procedia 2014, 61, 1352-1355. [CrossRef]

51. Remus, R.; Monsonet, M.A.A.; Roudier, S.; Sancho, L.D. Best available techniques (BAT) reference document for iron and steel production; Publications Office of the European Union: Brussels, Belgium, 2013.

52. World Steel Association. Worldsteel association $\mathrm{CO}_{2}$ emissions data collection. User Guide 2008, 6, 21.

53. WorldBank Commodity Markets. Available online: https:/www.worldbank.org/en/research/commoditymarkets (accessed on 17 June 2020).

54. Mandova, H.; Leduc, S.; Wang, C.; Wetterlund, E.; Patrizio, P.; Gale, W.; Kraxner, F. Possibilities for $\mathrm{CO}_{2}$ emission reduction using biomass in European integrated steel plants. Biomass Bioenergy 2018, 115, 231-243. [CrossRef]

55. NordPool. Day-Ahead Prices. Available online: https://www.nordpoolgroup.com/Market-data1/Dayahead/ Area-Prices/ALL1/Yearly/?view=table (accessed on 17 June 2020).

56. Moya, J.A.; Boulamanti, A. Production costs from energy-intensive industries in the EU and third countries; Publications Office of the European Union: Luxembourg, 2016.

(C) 2020 by the authors. Licensee MDPI, Basel, Switzerland. This article is an open access article distributed under the terms and conditions of the Creative Commons Attribution (CC BY) license (http://creativecommons.org/licenses/by/4.0/). 